\title{
Endothelial nitric oxide synthase G894T polymorphism increases the risk of infertility in women with endometriosis
}

\author{
R.C.P.C. e Silva ${ }^{1}$, L.C. de Faria ${ }^{2}$, K.S.F. e Silva ${ }^{5}$, K.K.V.O. Moura ${ }^{3}$, \\ C.L. Ribeiro Júnior ${ }^{4}$ and L.A. Guillo ${ }^{2}$ \\ ${ }^{1}$ Banco de Sangue, Unidade Transfusioanl, Hospital das Clínicas, \\ Universidade Federal de Goiás, Goiânia, GO, Brasil \\ ${ }^{2}$ Departamento de Bioquímica e Biologia Molecular, Universidade Federal \\ de Goiás, Goiânia, GO, Brasil \\ ${ }^{3}$ Departamento de Ciências Biológicas, Pontifícia Universidade Católica de \\ Goiás, Goiânia, GO, Brasil \\ ${ }^{4}$ Clinica Femina, Goiânia, GO, Brasil \\ ${ }^{5}$ Instituto de Ciências Biológicas, Universidade Federal de Goiás, Goiânia, \\ GO, Brasil
}

Corresponding author: L.A. Guillo

E-mail: lidia.guillo@gmail.com

Genet. Mol. Res. 18 (2): gmr18201

Received October 31, 2018

Accepted May 09, 2019

Published May 15, 2019

DOI http://dx.doi.org/10.4238/gmr18201

\begin{abstract}
Endometriosis is a chronic disease with adverse implications for fertility. We investigated the G894T polymorphism in the endothelial nitric oxide synthase gene in fertile and infertile women with endometriosis. This prospective study included a group of 52 women with a laparoscopic diagnosis of endometriosis. DNA was extracted from blood obtained from 47 patients and analyzed by PCR. The overall cohort was divided into infertile $(n=24)$ and fertile $(\mathrm{n}=23)$ subgroups and compared in terms of genotypic and allelic frequencies. The genotypic distribution followed Hardy-Weinberg equilibrium $\left(\chi^{2}=2.21, P=0.137\right)$ and included the GG genotype in $28 / 47$ GT in 14/47, and TT in 5/47 of the samples. Genotypic and allelic frequencies between fertile and infertile women with endometriosis showed that absence of the TT genotype was associated with fertility in endometriosis patients $(\mathrm{P}=0.0623)$. The $\mathrm{T}$
\end{abstract}


allele was present in 17 patients of the infertile group and 7 patients of the fertile group $(\mathrm{P}=0.025)$. This allele was significantly associated with infertility (relative risk $=2.21,95 \%$ confidence interval 1.56 - 3.08) for the recessive model of inheritance. Our findings suggest that women with endometriosis and the G894T polymorphism in the endothelial nitric oxide synthase gene are at increased risk of infertility.

Key words: Endometriosis; eNOS; Polymorphism; Infertility; Genotype

\section{INTRODUCTION}

Infertility associated with endometriosis impacts the reproductive lives of many women worldwide (Macer and Taylor, 2012). The clinical management of women with endometriosis-associated infertility is a difficult task, and currently available therapies to treat endometriosis do not always improve fertility (Pfeifer et al., 2012). Since endometriosis is considered a multifactorial disease, identification of the factors responsible for infertility in this setting is challenging. The detection of single nucleotide polymorphisms (SNP) may be a useful approach in this regard.

Nitric oxide (NO) has long been known to have an important role in endometrial function (Chwalisz and Garfield, 2000). In the normal human endometrium, NO is synthesized by endothelial and inducible NO synthase (eNOS and iNOS, respectively) isoforms. In the endometrium, eNOS is located in the glandular epithelium and microvascular endothelium and may be implicated in the initiation and maintenance of menstrual bleeding, inhibition of platelet aggregation, and myometrial relaxation during menstruation (Cameron and Campbell, 1998). The human eNOS gene is located on chromosome 7q35-36 (Marsden et al., 1998), and a common SNP with a G to T conversion at nucleotide position 894 changes the activity of the eNOS protein (Tesauro et al., 2000) and reduces basal NO production. Several diseases have been associated with such reduction in blood NO levels, including hypertension, atherosclerosis, and coronary artery disease (Veldman et al., 2002).

The eNOS G894T gene polymorphism has been associated with endometriosis at any stage (Zervou et al., 2003), at advanced stages (Kim et al., 2009) and enhances vascular response to phenylephrine (Philip et al., 1999). However, this finding has not been confirmed by other studies (Bhanoori et al., 2008). Administration of NO donor drugs has been proposed for the treatment of dysmenorrhea (Wetzka et al., 2001) and chronic pelvic pain (Maul et al., 2003), and for the management of early pregnancy disorders (Abdel et al., 2016). Since these conditions are often associated with low production of endogenous NO, we hypothesized that low NO levels produced by endometrial cells might be implicated in the physiopathology of endometriosis. To date, no polymorphic variants of the NO synthase gene have been associated with endometriosis-related infertility.

In an attempt to further clarify this issue, we investigated the occurrence of the eNOS G894T gene polymorphism in fertile and infertile women with endometriosis. The identification of a specific polymorphic variant of the eNOS gene associated with infertility may offer an opportunity to use NO donors to treat women with endometriosis-associated infertility. 


\section{MATERIAL AND METHODS}

This was a retrospective analysis of prospectively collected data. The study was approved by the Research Ethics Committee at the Federal University of Goiás (protocol number 0126.0.168.000-08) and was carried out in accordance with the Code of Ethics of the Declaration of Helsinki. All participants signed an informed consent form before enrollment. Sample size calculation, which takes into account the prevalence of endometriosis in the population, is challenging due to the need for visualizing the lesion during surgery (Ferrero et al., 2010). A study based on the UK General Practice Research Database reported a prevalence of endometriosis of 1.5\% (Ballard et al., 2008). Presuming a prevalence of $3 \%$, a sample size of 45 participants was calculated considering a number of 236,000 women aged 25-39 years (IBGE, 2010), with a margin of error of 5\% and a $95 \%$ confidence interval (CI). Indeed, the number of participants attending our clinic during the study period and included in the cohort was 52 .

\section{Patients}

The study included 52 women with a laparoscopic diagnosis of endometriosis attending a gynecology and obstetrics clinic in the city of Goiânia (Goiás, Brazil). The disease was staged according to the revised classification of the American Fertility Society (rAFS) and American Society for Reproductive Medicine (rASRM) (ASRM, 1985; ASRM, 1996). A sample of $10 \mathrm{~mL}$ of peripheral blood was drawn from each participant between 2009 and 2010 and stored for later analysis. During a personal interview, the participants answered a questionnaire collecting information on their age, self-reported skin color, presence and duration of symptoms (dysmenorrhea, bleeding, infertility), phase in the menstrual cycle in which the symptoms manifested, and lifestyle habits (smoking, alcohol, and physical activity). The classification of the participants into fertile and infertile followed the guidelines established by Zegers-Hochschild et al. (2017).

\section{Genotyping}

Genomic DNA was extracted using the $\mathrm{GFX}^{\mathrm{TM}}$ Genomic Blood Isolation Kit (Amersham Pharmacia Biotech, USA) according to the manufacturer's instructions and was stored at $-20^{\circ} \mathrm{C}$ for further analysis. The G894T polymorphism was genotyped by PCRrestriction fragment length polymorphism (PCR-RFLP), as described by Kim et al. (2009). PCR was performed in $45 \mu \mathrm{L}$ of PCR Master Mix (Quatro G Ltda, Porto Alegre, Brazil, containing $10 \mathrm{mM}$ Tris- $\mathrm{HCl}[\mathrm{pH}=8.5], 50 \mathrm{mM} \mathrm{KCl}, 1.7 \mathrm{mM} \mathrm{MgCl}_{2}, 0.2 \mathrm{mM}$ of each $\mathrm{dNTP}$, and $1.5 \mathrm{U}$ recombinant Taq polymerase) to which was added $0.2 \mathrm{mM}$ of each primer and 80-100 ng DNA, to a total volume of $50 \mu \mathrm{L}$. Amplification conditions included an initial denaturation at $94^{\circ} \mathrm{C}$ for $5 \mathrm{~min}$, followed by 30 cycles at $94^{\circ} \mathrm{C}, 58^{\circ} \mathrm{C}$, and $72^{\circ} \mathrm{C}$ for denaturation, annealing, and extension, respectively, with 1 minute for each step and a final extension time of $10 \mathrm{~min}$ at $72^{\circ} \mathrm{C}$, according to Kim et al. (2009). The primers used in the analysis were synthesized according to the sequences reported by these same authors (Kim et al., 2009). For restriction enzyme analysis, a total of $10 \mu \mathrm{L}$ of the PCR reaction mixture (no more than one-third of the volume of digestion reaction mixture to avoid inhibitory effects) was added to restriction enzyme buffer (10 mM Tris- $\mathrm{HCl}$ [pH 7.9], $50 \mathrm{mM} \mathrm{NaCl}$, 
$10 \mathrm{mM} \mathrm{MgCl}$, and $1 \mathrm{mM}$ DTT) to which was added 10 units (U) of the restriction enzyme MboI (10 U/ $\mu \mathrm{L}$, Promega, USA), $2 \mu \mathrm{g}$ acetylated BSA $(10 \mu \mathrm{g} / \mu \mathrm{L}$, provided with the restriction enzyme) to a final digestion volume of $30 \mu \mathrm{L}$. Digestion was run in a digital thermomixer (Vortemp 56, Labnet Inc, USA) at $400 \mathrm{rpm}$ and $37^{\circ} \mathrm{C}$ for $6 \mathrm{~h}$. Samples carrying the $\mathrm{T}$ allele were cleaved into 119 and $87 \mathrm{bp}$ fragments. The $\mathrm{G}$ allele remained uncleaved with $206 \mathrm{bp}$ (Figure 1). Aliquots of $6 \mu \mathrm{L}$ of loading buffer with Gel Red 5X (Quatro G, Porto Alegre, Brazil) were added to $24 \mu \mathrm{L}$ of digestion products and separated by gel electrophoresis (3\% agarose in $1 \mathrm{X}$ TBE buffer). Gel images were visualized using Gel Documentation (BioRad, USA).

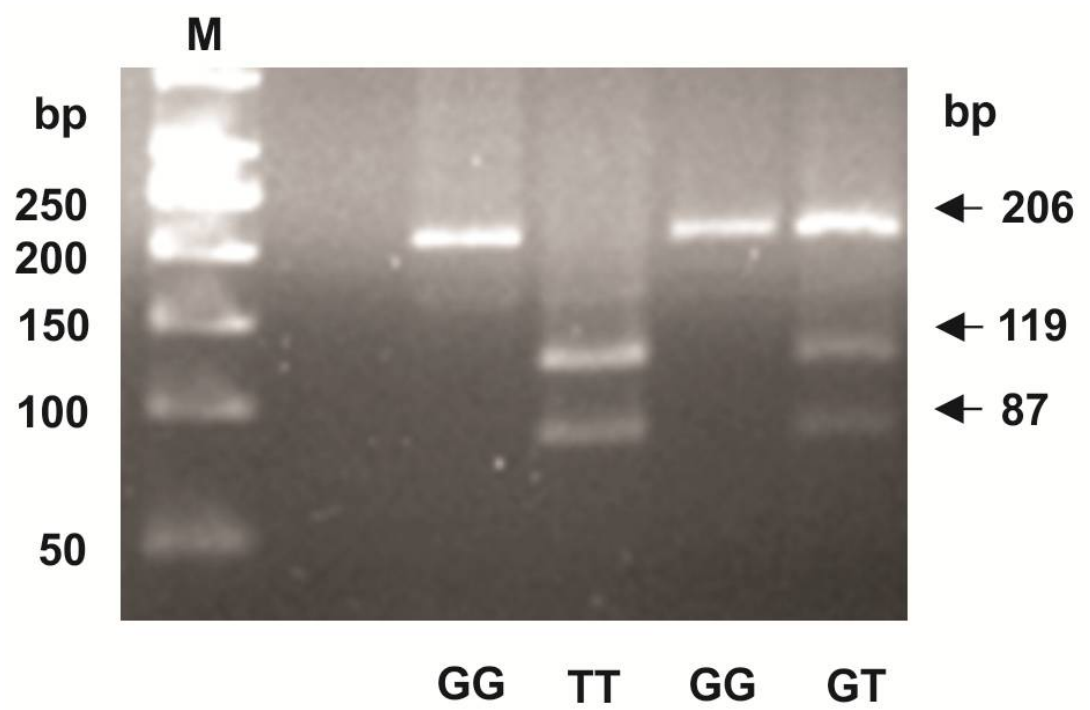

Figure 1. Agarose gel electrophoresis of the PCR products digested with the restriction enzyme MboI to assess the G894T polymorphism in DNA isolated from blood samples. Samples carrying the T allele were cleaved into 119 e 87 bp fragments (arrow heads). The G allele remained uncleaved with 206 bp (arrow head). Shown are representative results of each genotype. M, marker lane: ladder 50 bp (Quatro G, Brazil).

\section{Statistical analysis}

Women with endometriosis were distributed into fertile and infertile groups, and frequencies of clinical and social habits were calculated and compared by the chi-square test $\left(\chi^{2}\right)$. Age-related data are presented as mean \pm standard deviation (SD) and were tested for normality with the Kolmogorov-Smirnov test. The parametric Student's $t$ test was used to assess differences between the groups. Frequencies of genotypes for all participants were distributed according to endometriosis staging and were compared using the chi-square test. Hardy-Weinberg equilibrium was tested with the chi-square test. Relative risk (RR) and 95\% CI associated with genotypes and alleles were calculated using $2 \times 2$ contingency tables. All analyses were performed using the software GraphPad Prism 5 for Windows, version 5.01 (GraphPad, San Diego, CA, USA) and a P value lower than 0.05 was considered statistically significant. 


\section{RESULTS}

\section{Characteristics of the cohort study}

The cohort comprised 52 women with endometriosis with a mean age of $33.3 \pm 2.9$ years. The mean age was $34.0 \pm 3.0$ years among fertile patients and $32.7 \pm 2.7$ years among infertile ones. There was no significant difference in age $(\mathrm{P}=0.072)$ between women with and without infertility. Among all participants, 28 were infertile. Table 1 shows the clinical data and social habits of all 52 patients with endometriosis distributed according to fertility condition.

Table 1 - Distribution of clinical and demographic characteristics among women with endometriosis according to fertility condition.

\begin{tabular}{|c|c|c|c|}
\hline & $\begin{array}{l}\text { Condition } \\
\text { Fertile } \\
\end{array}$ & Infertile & P value $^{1}$ \\
\hline & $\mathrm{n}$ & $\mathrm{n}$ & \\
\hline Self-reported ethnicity & & & 0.674 \\
\hline White & 22 & 24 & \\
\hline Black & 2 & 4 & \\
\hline Major symptoms & & & ND \\
\hline Pelvic pain & 15 & - & \\
\hline Intense pelvic pain & 9 & - & \\
\hline Infertility & - & 28 & \\
\hline Other symptoms & & & ND \\
\hline None reported & 12 & - & \\
\hline Pelvic pain & - & 12 & \\
\hline Intense pelvic pain & - & 10 & \\
\hline Bleeding & 9 & - & \\
\hline Bleeding and pelvic pain & - & 4 & \\
\hline Endometrioma & 3 & - & \\
\hline Endometrioma and intense pelvic pain & - & 2 & \\
\hline Duration (years) & & & 0.260 \\
\hline 0 to $<3$ & 13 & 9 & \\
\hline 3 to $<6$ & 8 & 15 & \\
\hline 6 to $<8$ & 3 & 3 & \\
\hline Period of the menstrual cycle & & & 0.006 \\
\hline Premenstrual & 1 & 7 & \\
\hline Premenstrual and menstrual & 14 & 5 & \\
\hline The entire menstrual cycle & 9 & 15 & \\
\hline R-ASRM classification ${ }^{\mathrm{a}, \mathrm{b}}$ & & & 0.585 \\
\hline I & 4 & 7 & \\
\hline II & 7 & 4 & \\
\hline III & 8 & 11 & \\
\hline IV & 5 & 5 & \\
\hline Physical activity & & & 0.192 \\
\hline None & 7 & 11 & \\
\hline Mild & 14 & 9 & \\
\hline Moderate & 3 & 7 & \\
\hline Smoking & & & 0.623 \\
\hline Yes & 1 & 2 & \\
\hline No & 23 & 25 & \\
\hline Alcohol & & & 0.542 \\
\hline Yes & 3 & 2 & \\
\hline No & 21 & 25 & \\
\hline
\end{tabular}


We observed that 46 of the 52 women with endometriosis were of self-reported White ethnicity, which was reported by 22 of the 24 fertile patients and 24 of the 28 infertile ones. The statistical analysis showed no significance between fertile and infertile patients in relation to the self-declared skin color $(\mathrm{P}=0.503)$. The main clinical symptoms associated with endometriosis were infertility (28/52), chronic pelvic pain (15/52), and intense chronic pelvic pain (9/52). As shown in Table 1, pelvic pain had a high frequency among fertile women. This symptom was reported in the item other symptoms by 12 of the 28 infertile women. Bleeding accompanied by pelvic pain was reported by 4 of the 28 infertile women.

The duration of the symptoms until the diagnosis of endometriosis ranged from 3 to 6 years in 24 patients participants. Among infertile women, 15 patients reported symptom duration between 3 and 6 years, with a shorter duration (0 to 3 years) among most fertile patients (13/24). However, the statistical analysis indicated no significant difference between fertile and infertile patients in relation to symptom duration. Concerning the period of the menstrual cycle in which the symptoms appear, we observed a significant difference between fertile and infertile patients $(\mathrm{P}=0.006)$. Thus, the symptoms were more frequent in the premenstrual plus menstrual periods in 14 of the 24 fertile women and only in the premenstrual period in 7 infertile patients. The factors responsible for this difference and the impact of such difference on infertility are unclear.

The most prevalent endometriosis stage was III, found in 19 of 51 patients. This was also the most frequent stage found both in fertile and infertile women (8/24 and $11 / 29$, respectively). No significant difference was observed in regards to stage level between fertile and infertile women $(\mathrm{P}=0.585)$. We also observed that most patients with endometriosis were nonsmokers (48/51) or alcohol consumers (46/51). Finally, with respect to the practice of physical activity, we observed that most women with endometriosis (41/51) reported not practicing (or practicing mild) physical activity.

\section{Endothelial nitric oxide polymorphism analysis}

Out of the 52 samples included in the study, 5 had insufficient DNA for analysis and were excluded ( 3 and 2 in the fertile and infertile groups, respectively). The distribution of the genotypes followed the Hardy-Weinberg equilibrium $\left(\chi^{2}=2.21, \mathrm{P}=\right.$ 0.137 ) and included the GG genotype in 28 , GT in 14, and TT in 5 of the patients.

The genotypic and allelic frequencies of the fertile and infertile women with endometriosis included in the study are shown in Table 2 . We observed that the TT genotype was absent in all 23 fertile women and present in 5 of 24 infertile patients $(\mathrm{P}=$ 0.062 ). Additionally, the frequency of the $\mathrm{T}$ allele was $35.4 \%$ in the infertile group and $15.2 \%$ in the fertile one $(\mathrm{P}=0.025)$ (Table 2). The presence of this allele was significantly associated with infertility risk $(\mathrm{RR}=2.21,95 \% \mathrm{CI} 1.59-3.08, \mathrm{P}=0.021)$ for the recessive and codominant models of inheritance. 
Table 2. Genotypic and allelic distribution of G894T polymorphism in patients with endometriosis according to fertility condition.

\begin{tabular}{|c|c|c|c|c|c|}
\hline & \multicolumn{5}{|c|}{ Endometriosis condition } \\
\hline & Infertile $(n=24)$ & Fertile $(n=23)$ & $\mathbf{P}^{*}$ & $\mathbf{R}$ *** & $95 \%$ CI \\
\hline \multicolumn{6}{|l|}{ Genotypes } \\
\hline GG & 12 & 16 & 0.062 & & \\
\hline GT & 7 & 7 & & & \\
\hline \multirow{2}{*}{\multicolumn{6}{|c|}{ Alleles }} \\
\hline & & & & & \\
\hline G & 31 & 39 & 0.025 & 1.60 & $1.11-2.31$ \\
\hline $\mathrm{T}$ & 17 & 7 & & & \\
\hline \multicolumn{6}{|l|}{ Inheritance model } \\
\hline \multicolumn{6}{|c|}{ Codominant } \\
\hline GG & 12 & 16 & 0.019 & 2.33 & $1.52-3.58$ \\
\hline TT & 5 & 0 & & & \\
\hline \multicolumn{6}{|l|}{ Recessive } \\
\hline TT & 5 & 0 & 0.021 & 2.21 & $1.59-3.08$ \\
\hline $\mathrm{GT}+\mathrm{GG}$ & 19 & 23 & & & \\
\hline \multicolumn{6}{|l|}{ Dominant } \\
\hline $\mathrm{GT}+\mathrm{TT}$ & 12 & 16 & 0.172 & 0.68 & $0.39-1.17$ \\
\hline GG & 12 & 7 & & & \\
\hline
\end{tabular}

*P: values were calculated with the chi-square test. **RR: relative risk

\section{DISCUSSION}

We found that the eNOS G894T polymorphism was a risk factor for the development of infertility in women with endometriosis. To the best of our knowledge, this is the first time that this association is reported, although some inferences have been made regarding eNOS and patients with endometriosis during the menstrual cycle (Ota et al., 2008). Two out of three studies concerning G894T polymorphism and endometriosis (Zervou et al., 2003; Bhanoori et al., 2008; Kim et al., 2009) have shown that the heterozygous and homozygous genotypes were associated with risk of endometriosis when women without endometriosis were used as controls. Among women with endometriosis, the frequency of infertility was consistent with results from other studies reporting rates about 30 to 50\% (Macer and Taylor, 2012). The majority of the participants in our study were of white ethnicity.

Interestingly, endometriosis was less prevalent among African-American women in a study conducted in the United States (Ballard et al., 2008). Considering the skin phototype, Missmer et al. (2004) observed a two-fold increase in the risk of development of the disease among women with a photosensitive phenotype (skin burn in reaction to sun exposure). Due to the limitations of our study, we are unable to make inferences or comparisons, but it was intriguing to observe a larger proportion of white women in relation to black ones seeking care with suspected endometriosis, considering that the city of Goiânia has a balanced proportion (49\%) of white and black/mulatto women (IBGE, 2010). It is important to emphasize, however, that patients were attended in a private clinic. Thus, socioeconomic factors and the geographic location may have contributed to a higher proportion of white women in relation to black/mulato women seeking care for suspected endometriosis. 
We observed no significant differences between fertile and infertile women with endometriosis in terms of age, symptom duration before diagnosis, complaint of bleeding, presence of endometrioma, and stage of endometriosis. Therefore, a potential bias from these confounding variables was minimized in our study, and the RR values required no adjustment. The presence of symptoms in the premenstrual phase of the cycle was significantly more frequent in infertile women with endometriosis when compared with fertile ones. According to Khorram and Lessey (2002) the symptoms presented by premenstrual phase women can be a clinical predictor of infertility in endometriosis, due to alterations in the expression of certain important proteins, such as eNOS. The identification of such alterations would help clinicians improve the management of infertility in women with endometriosis (Whitehill et al., 2012; Heitmann et al., 2014). It is interesting to note that results from a recent multicenter study have shown a delay of 6.7 years between the onset of symptoms and a surgical diagnosis of endometriosis, although this period may increase to 8.3 years in countries in which women rely on state-funded health care (Nnoaham et al., 2011).

Most patients with endometriosis in our study were nonsmokers, in contrast to recent studies that have shown a positive association between smoking and endometriosis (Saha et al., 2016). Additionally, most women with endometriosis reported not practicing (or practicing mild) physical activity, which corroborates the findings of studies showing that the practice of physical activity decreases the risk of endometriosis (Vitonis et al., 2010).

After collecting the clinical data and verifying possible associations with the eNOS G894T polymorphism, we focused mainly on the clinical endometriosis stage. As recently reported, moderate and severe endometriosis are associated with a greater genetic burden compared with minimal or mild disease (Sapkota et al., 2015). The frequencies of the GG+GT genotypes in stages I/II and III/IV were $94 \%$ and $89 \%$, respectively, whereas those of the TT genotypes were $6 \%$ and $11 \%$, respectively. We observed an increased frequency of the TT genotype in women with the classification III/IV, but this finding was not significant $(\mathrm{P}=0.545)$. Other clinical features were not tested for associations with the G894T polymorphism due to the small sample size of our cohort. When we compared genotypes between fertile and infertile women, we observed a significant 1.6-fold increased frequency of the $\mathrm{T}$ allele in infertile women with endometriosis when compared with fertile ones.

In the normal human endometrium, eNOS is regulated by estrogen and progesterone (Han et al., 2005; Khorram et al., 2009; Silva et al., 2016) and is expressed in the glandular and endometrial microvascular epithelium during the luteal phase (Cameron and Campbell et al., 1998). Therefore, synthesis of adequate NO levels is required for proper hormonal signaling.

Interestingly, women with unexplained infertility have been shown to have increased eNOS expression in the glandular and luminal epithelium of the endometrium, which has lead authors to suggest a detrimental effect of NO excess in receptivity and implantation (Najafi et al., 2012). However, it is unclear in these studies which eNOS polymorphic variant is overexpressed. Functional studies have shown that the TT variant may have diminished catalytic activity with implications in cardiopulmonary diseases (Tesauro et al., 2000). 
Since we observed an increased frequency of the TT genotype of the eNOS gene in infertile women with endometriosis, we hypothesize that NO levels produced in the endometrium by the eNOS enzyme may be lower than those found in fertile ones bearing the wild-type genotype. In this regard, treatment with NO donors may contribute to improving blastocyst implantation in infertile women with endometriosis, as already verified in patients with unexplained infertility (Abdel et al., 2013).

The search for ideal controls in studies on endometriosis is a difficult task considering that laparoscopy, an invasive procedure, is required to confirm the diagnosis of the disease. For this reason, we did not include controls in our study. However, we are considering in future studies the selection of healthy women undergoing tubal ligation by videolaparoscopy, thus minimizing the ethical concerns involving this surgical procedure.

The findings of this study suggest that women with endometriosis bearing the G894T polymorphism in the eNOS gene are at increased risk of infertility. Considering that up to now a convincing genetic contribution to the risk of development of endometriosis has not been found, we believe that the screening for this polymorphism in a large number of infertile women with diagnosed endometriosis will help the development of new strategies to prevent the progression of women with endometriosis to infertility. The use of NO donors could be an alternative treatment to prevent infertility associated with endometriosis.

\section{ACKNOWLEDGMENTS}

We would like to express our heartfelt thanks to all the women who kindly volunteered to donate blood. We also would like to thank and the Postgraduation Program in Health Sciences at UFG, for partially financing the study, and the Centro de Medicina Fetal e Reprodução Humana (FERTILE, Goiânia). L.C.F. was supported by a grant from CAPES (Coordenação de Aperfeiçoamento de Pessoal de Nível Superior).

\section{CONFLICTS OF INTEREST}

The authors declare no conflict of interest.

\section{REFERENCES}

Abdel RM, El-Berry S, El-Nezamy A, Saad A, et al. (2016). Nitric oxide donors increase the pregnancy rate in patients with unexplained infertility undergoing clomiphene citrate stimulation and intrauterine insemination: a randomized controlled pilot study. Gynecol. Endocrinol. 33: 199-202.

Ballard KD, Seaman HE, de Vries CS and Wright JT (2008). Can symptomatology help in the diagnosis of endometriosis? Findings from a national case-control study--Part 1. BJOG. 115 (11): 1382-1391.

Bhanoori M, Kameshwari DB, Zondervan KT, Deenadayal M, et al. (2008). The endothelial nitric oxide synthase Glu298Asp polymorphism is not a risk factor for endometriosis in south Indian women. Eur. J. Obstet. Gynecol. Reprod. Biol. 139: 53-8.

Cameron IT and Campbell S (1998). Nitric oxide in the endometrium. Hum. Reprod. Update. 4: 565-9.

Chwalisz K and Garfield RE (2000). Role of nitric oxide in implantation and menstruation. Hum Reprod. 15: 96-111.

Ferrero S, Arena E, Morando A, Remorgida V (2010). Prevalence of newly diagnosed endometriosis in women attending the general practitioner. Int. J. Gynaecol. Obstet. 110: 203-207.

Han G, Magee T and Khorram O (2005). Regulation of nitric oxide synthase isoforms by estrogen in the human endometrium. Fertil Steril. 84: 1220-7.

Heitmann RJ, Langan KL, Huang RR, Chow GE, et al. (2014). Premenstrual spotting of >/=2 days is strongly associated with histologically confirmed endometriosis in women with infertility. Am. J. Obstet. Gynecol. 211: 358 e1-6.

IBGE - Instituto Brasileiro de Geografia e Estatística. Censo Demográfico. (2010). Available from: URL:

http://www.goiania.go.gov.br/shtml/seplam/anuario2012/_html/d_populacao.html. Accessed October 10, 2018. 
Khorram O and Lessey BA (2002). Alterations in expression of endometrial endothelial nitric oxide synthase and alpha(v)beta(3) integrin in women with endometriosis. Fertil Steril. 78: 860-4.

Khorram O and Han G. (2009). Influence of progesterone on endometrial nitric oxide synthase expression. Fertil Steril. 91: 2157-62.

Kim H, Ku SY, Kim SH, Lee GH, et al. (2009). Endothelial nitric oxide synthase gene Glu298Asp polymorphism is associated with advanced stage endometriosis. Hum. Reprod. 24: 2656-9.

Macer ML and Taylor HS (2012). Endometriosis and infertility: a review of the pathogenesis and treatment of endometriosis-associated infertility. Obstet. Gynecol. Clin. North Am. 39: 535-49.

Marsden PA, Heng HH, Scherer SW, Stewart RJ, et al. (1993). Structure and chromosomal localization of the human constitutive endothelial nitric oxide synthase gene. J. Biol. Chem. 268: 17478-88.

Maul H, Longo M, Saade GR and Garfield RE (2003). Nitric oxide and its role during pregnancy: from ovulation to delivery. Curr. Pharm. Des. 9: 359-80.

Missmer SA, Hankinson SE, Spiegelman D, Barbieri RL, et al. (2004). Incidence of laparoscopically confirmed endometriosis by demographic, anthropometric, and lifestyle factors. Am. J. Epidemiol. 160: 784-96.

Najafi T, Novin MG, Ghazi R and Khorram O (2012). Altered endometrial expression of endothelial nitric oxide synthase in women with unexplained recurrent miscarriage and infertility. Reprod. Biomed. Online. 25: 408-14.

Nnoaham KE, Hummelshoj L, Webster P, d'Hooghe T, et al. (2011). Impact of endometriosis on quality of life and work productivity: a multicenter study across ten countries. Fertil Steril. 96: 366-73 e8.

Ota H, Igarashi S, Hatazawa J and Tanaka T (1998). Endothelial nitric oxide synthase in the endometrium during the menstrual cycle in patients with endometriosis and adenomyosis. Fertil Steril. 69: 303-8.

Pfeifer S, Fritz M, Goldberg J, McClure R, et al. (2012). Endometriosis and infertility: a committee opinion. Fertil Steril. 98: 591-8.

Philip I, Plantefeve G, Vuillaumier-Barrot S, Vicaut E, et al. (1999). G894T polymorphism in the endothelial nitric oxide synthase gene is associated with an enhanced vascular responsiveness to phenylephrine. Circulation. 99: 3096-8.

Revised American Fertility Society classification of endometriosis: 1985. Fertil Steril. 43: 351-2.

Revised American Society for Reproductive Medicine classification of endometriosis, 1997: Fertil Steril. 67: 817-21.

Saha R, Kuja-Halkola R, Tornvall P and Marions L (2016). Reproductive and Lifestyle Factors Associated with Endometriosis in a Large Cross-Sectional Population Sample. J. Womens Health. 26: 152-8.

Sapkota Y, Attia J, Gordon SD, Henders AK, et al. (2015). Genetic burden associated with varying degrees of disease severity in endometriosis. Mol. Hum. Reprod. 21: 594-602.

Silva RCPC, Moura KKVO, Ribeiro Junior CL and Guillo, LA (2016). Estrogen signaling in the proliferative endometrium: implications in endometriosis. Rev. Assoc. Med. Bras. 62: 72-7.

Tesauro M, Thompson WC, Rogliani P, Qi L, et al. (2000). Intracellular processing of endothelial nitric oxide synthase isoforms associated with differences in severity of cardiopulmonary diseases: cleavage of proteins with aspartate vs. glutamate at position 298. Proc. Natl. Acad. Sci. USA. 97: 2832-5.

Veldman BA, Spiering W, Doevendans PA, Vervoort G, et al. (2002). The Glu298Asp polymorphism of the NOS 3 gene as a determinant of the baseline production of nitric oxide. J. Hypertens. 20: 2023-7.

Vitonis AF, Hankinson SE, Hornstein MD and Missmer SA (2010). Adult physical activity and endometriosis risk. Epidemiology. 21: 16-23.

Wetzka B, Schafer WR, Stehmans A and Zahradnik HP (2001). Effects of nitric oxide donors on the contractility and prostaglandin synthesis of myometrial strips from pregnant and non-pregnant women. Gynecol. Endocrinol. 15: 3442.

Whitehill K, Yong PJ and Williams C (2012). Clinical predictors of endometriosis in the infertility population: is there a better way to determine who needs a laparoscopy? J. Obstet. Gynaecol. Can. 34: 552-7.

Zegers-Hochschild F, Adamson GD, Dyer S, Racowsky C, et al. (2017). The International Glossary on Infertility and Fertility Care. Fertil Steril. 108 (3): 393-406.

Zervou S, Karteris E, Goumenou AG, Vatish M, et al. (2003). The Glu298-->Asp polymorphism of the endothelial nitric oxide synthase gene is associated with endometriosis. Fertil Steril. 80: 1524-5. 